University of Nebraska - Lincoln

DigitalCommons@University of Nebraska - Lincoln

1967

\title{
Ontogeny and Anatomy of the Flower of Limnocharis flava (Butomaceae)
}

Robert B. Kaul

University of Nebraska-Lincoln

Follow this and additional works at: https://digitalcommons.unl.edu/bioscifacpub

Part of the Biology Commons, and the Botany Commons

Kaul, Robert B., "Ontogeny and Anatomy of the Flower of Limnocharis flava (Butomaceae)" (1967). Faculty Publications in the Biological Sciences. 845.

https://digitalcommons.unl.edu/bioscifacpub/845

This Article is brought to you for free and open access by the Papers in the Biological Sciences at DigitalCommons@University of Nebraska - Lincoln. It has been accepted for inclusion in Faculty Publications in the Biological Sciences by an authorized administrator of DigitalCommons@University of Nebraska - Lincoln. 
Kaul in American Journal of Botany (November-December 1967) 54(10): 1,223-1,230.

COPYRIGHT 1967, WILEY. USED By PERMISSION.

\title{
Ontogeny and Anatomy of the Flower of Limnocharis flava (Butomaceae)
}

\author{
Robert B. Kaul \\ Department of Botany, University of Nebraska, Lincoln
}

\begin{abstract}
The flowers of Limnocharis flava (L.) Buch. are borne in an indeterminate umbel and each consists of three sepals, three yellow petals, and about 18 carpels surrounded by numerous stamens and staminodia. The androecium is centrifugally developed, and the last-formed members are staminodial; it is supplied by branching vascular systems. Carpels arise almost simultaneously, and a prominent residual floral apex remains. The carpels are partially conduplicately closed and are also primitive in possessing laminar placentation and in lacking differentiation of a style. The gynoecium is essentially apocarpous, but there are slight fusions of adjacent carpels near their ventral margins where they are attached to the receptacle. It is suggested that the Limnocharis flower is the most primitive in the family.
\end{abstract}

The Butomaceae are considered by many to be among the most primitive of the monocotyledons, yet little anatomical work has been done on them. Saunders (1929) and Singh (1966a) studied the floral anatomy of Butomus umbellatus, and its development has been described by Payer (1857) and Buchenau (1857). Ronte (1891) and Eber (1934) studied the floral morphology of Hydrocleis nymphoides and of Limnocharis flava, and Saunders (1929) studied the floral anatomy of $\mathrm{Hy}$ drocleis nymphoides. The writer (1964) has investigated some aspects of the structure of mature flowers of Butomus Hydrocleis, Limnocharis, and Tenagocharis. Centrifugal development of the androecium of Limnocharis flava and that of Hydrocleis nymphoides was noted by Ronte (1891), but it has been overlooked (Corner, 1946; Eames, 1961) until recently. No other monocotyledonous genera are known to possess such a developmental pattern. Troll (1932) studied the gynoecium of Limnocharis flava and proposed a pattern of modification of gynoecia in the family.

The present study has been undertaken to attempt to clarify by ontogenetic study certain positional relationships among various organs which are not readily apparent in the mature flowers. Special attention has also been given to the fate of the floral apex, to the relationship between the carpels and the floral apex, and to the vascular anatomy of the mature flower.

\section{Materials and Methods}

Inflorescences in all stages of development from plants collected by the author in Ceylon, Malaya, and North Borneo were fixed in FAA. Flowers from the larger inflorescences were removed and embedded in paraffin while smaller inflorescences were embedded whole. Determination of relative ages of the flowers is simplified by the fact that they are borne in an easily traced spiral phyllotaxy. Transverse and longitudinal sections at 15 $\mu$ were made of both single flowers and entire inflorescences and were stained with safranin and fast green. Flowers larger than $1 \mathrm{~mm}$ in diam were also cleared in $5 \% \mathrm{NaOH}$, rinsed, and stored in lactic acid for study without staining. Some of the cleared flowers were also stained with safranin and crystal violet and stored in xylene.

\section{Observations}

\section{General organography}

Limnocharis flava (L.) Buchenau is the only representative of this genus of South American emergent aquatics. It has been extensively introduced into southeast Asia where it is sometimes grown for human and animal food. The inflorescence is an indeterminate umbel whose peduncle after flowering may bend downward and assume the role of a stolon, with growth of a new

Received for publication February 1, 1967. Financial support for collection and study has been provided by the National Science Foundation and the Society of the Sigma Xi. 
plant proceeding from the vegetative apex within the umbel. Two to 15 or more flowers are produced in each inflorescence, and each flower is subtended by a large bract. The flower consists of three green sepals alternating with three light yellow petals with darker yellow bases. The numerous stamens are surrounded by less numerous staminodia, which apparently serve as nectaries, and the entire androecium is borne at maturity on a slightly raised shoulder below the 18 or so carpels (Figure 13). There are no important fusions within the flower except for the partial union of the ventral carpel margins to each other and to the elongated floral axis. The flower opens early in the day and closes in a few hours, and the petals and androecium disintegrate very soon thereafter.

\section{Floral ontogeny}

Following initiation of the bract from the inflorescence apex, the rounded floral primordium may be seen arising as a mass of densely staining cells. One tunica layer is discernible (Figure 9, left). Continuing growth of this primordium results in an early differentiation of the pedicel. The pedicel undergoes rapid elongation and begins to assume its triangular shape, and the floral apex broadens. Initiation of procambium proceeds acropetally up the pedicel and into the developing perianth (Figure 9, right). By the time the floral primordium has reached this stage there are at least two tunica layers present. Sepals are the first appendages to appear, arising in spiral succession. The first sepal primordium is initially the largest of the three and it remains so. The petals arise simultaneously soon thereafter. The floral apex above the perianth primordia is now about $0.5 \mathrm{~mm}$ high and about $0.5 \mathrm{~mm}$ wide and the first external evidence of the androecium develops when three or more slight protuberances appear beside each other opposite the first sepal (Figures 1 and 9). Each represents a single-stamen primordium. About three stamen primordia then appear successively above each of the other two sepals (Figure 1). The second whorl arises in a similar pattern beneath the first, and its members are alternate with those of the first (Figure 2). The next stamens to arise are those opposite the petals; they appear to arise simultaneously in groups of approximately three almost coincident with the second antisepalous stamens. The antisepalous stamens retain their slight developmental lead over the antipetalous ones, although crowding and expansion of the receptacle tend to obliterate true positional relationships. Following initiation of the stamens the staminodia appear in continuation of the centrifugal sequence. Extreme crowding of the staminodial primordia between the developing perianth below and the stamens above obscures any whorled pattern which they might possess. The innermost, first-formed stamens (Figure 8) at maturity are shorter and have broader filaments than the subsequently formed stamens (Figures 4 and 7). The staminodia are awl-shaped and vary in height from 2 to $15 \mathrm{~mm}$ (Figures 4-6). All members of the androecium are aerenchymatous (Figure 14). The stamens and staminodia do not intergrade and the transition between them is sudden and distinct. Meiosis occurs first in the innermost stamens.

Shortly after initiation of the first stamens, and well before initiation of the outermost staminodia, the carpel primordia appear just above the stamen primordia. They arise on the sides of the floral apex and leave a large residual apex (Figures 2, 11, and 12). This residual floral apex is evident for the life of the flower, and it is not obscured by the numerous developing carpels on its flanks. The antisepalous carpels appear slightly ahead of the antipetalous ones (Figure 2), but these two groups are not sharply defined. Each carpel primordium consists of a darkly staining crescent-shaped mass of cells which is meristematic throughout. Up to anthesis the carpel primordia remain crescentshaped in cross section, but the arms of the crescents elongate considerably. At anthesis each carpel consists of two relatively thin arms directed inward from the thicker dorsal part of the carpel (Figure 14). The carpel is narrower apically but there is no differentiation of a style. The stigmatic areas occupy the ventral margins in the region above the separation of the carpel margins from 
Figure 1. Flower primordium just after initiation of first stamens, X 120. | Figure 2. Later stage after initiation of all carpels. Antisepalous carpels are slightly older. Outer members of androecium not yet formed. Residual floral apex prominent, X 70. | Figure 3. Still older stage with sepals removed and some stamens and staminodia cut away. Inner, first-formed stamens at this stage larger than outer ones. Staminodia beginning to elongate. Prominent residual floral apex shown, X 60. | Figure 4. Flower at anthesis with sepals, two petals, and some stamens and staminodia cut away. Mature petal shown. Inner stamens are overtopped by later stamens and many staminodia. Residual floral apex obscured by carpels in this view, cf. Figure 13, X 12. | Figures 5 and 6. Staminodia, X 18. | Figure 7. Stamen of intermediate size at anthesis, adaxial view, X 18. | Figure 8. First-formed and smallest stamen, adaxial view, X18.
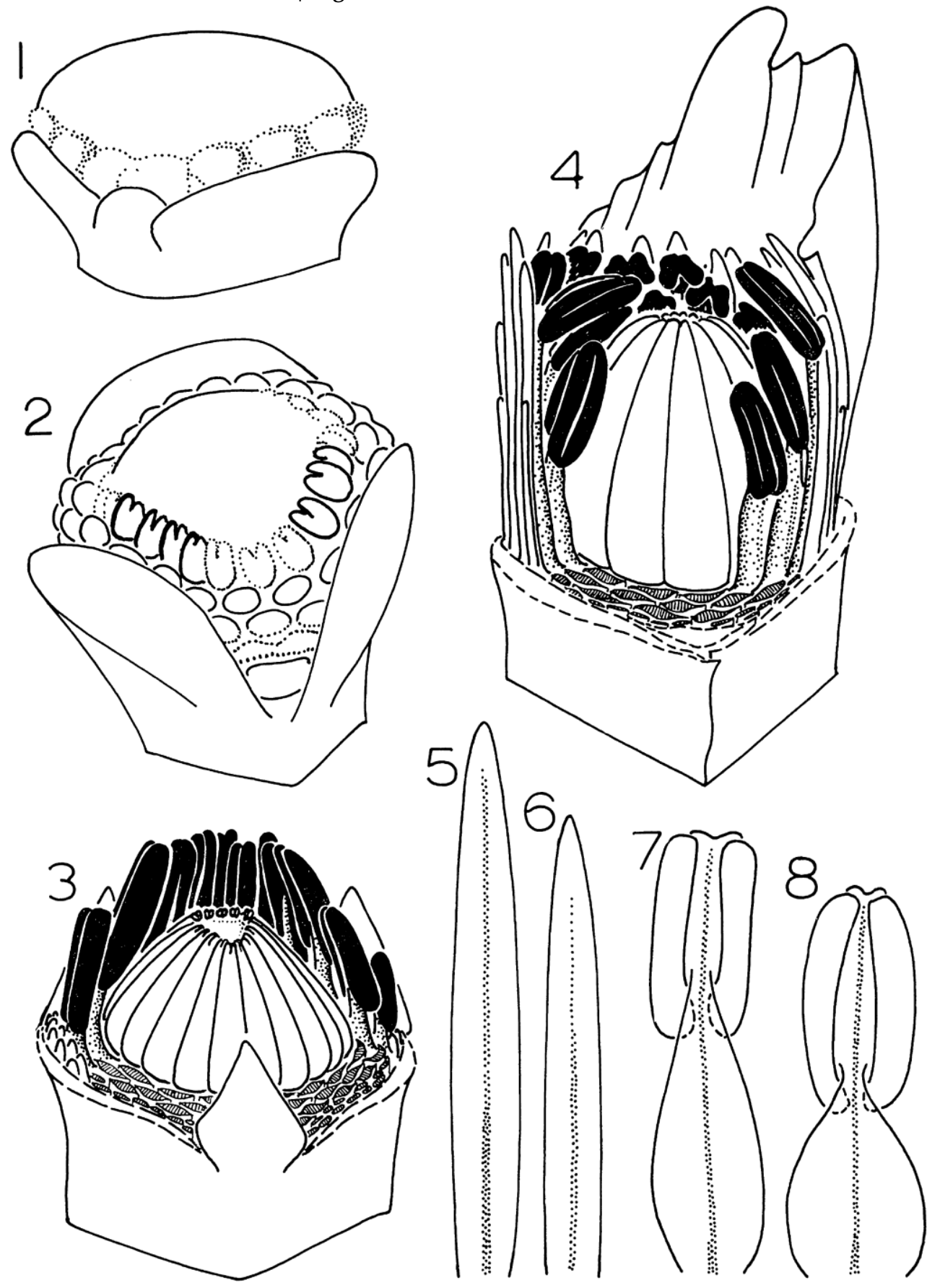
the receptacle (Figure 16). From the time of their inception until anthesis the rate of elongation of the carpels is paced by that of the floral apex, and at anthesis the stigmatic regions are only slightly above the top of the axis (Figures 13 and 16). Fusion of the ventral carpellary margins to the receptacle is congenital (Figures 10-13).

Each carpel bears two large placentae on its adaxial surface. The placentae do not extend to the carpel margins nor do they cover the area near the dorsal bundle (Figures 14 and 16). The first indication of differentiation of the placental regions is delimitation of darkly staining epidermal and sub-epidermal layers on the adaxial surfaces of the carpel laminae. At this stage the ventral margins of the carpel are weakly fused with each other and are clearly fused with the floral axis. The first ovules are initiated closest to the dorsal bundle about halfway up the locule. Although the ventral margins of each carpel are conduplicately appressed and fused (Figure 14), adjacent carpels are free from each other except for slight fusions of adjacent abaxial surfaces where they are crowded together at the junctures with the axis. As the carpel matures after anthesis the walls become dry and the laminae become papery and pull away from the receptacle if the fruits remain above water. The result is a completely open follicle. Maturation of the carpels takes place in about a week following anthesis.

The very young flower primordium is round in cross section, but as growth continues the symmetry changes and it becomes triangular. Figure 1 shows a flower just prior to initiation of the carpels when the axis is still roughly circular in cross section, and Figures 2-4 show the progressive development of the triangular character of the entire flower. Even the residual floral apex is triangular in section (Figure 14). The change in symmetry of the floral axis is accompanied by an increase in diameter in the region below the attachment of the carpels. The broadening axis develops shoulders upon which the stamens and staminodia and perianth are borne. The later-formed members of the androecium, which are at first clearly borne below the level of the first whorl of stamens (Figures 2 and 10), assume positions outside of, and later actually slightly above, that first whorl (Figures 3, 4, 12, and 13).

\section{Vascular anatomy}

In the center of the pedicel there are six bundles which are larger than the numerous peripheral bundles. The three bundles opposite the sides of the triangular pedicel supply the sepals and the three bundles opposite the angles of the pedicel supply the petals, androecium, and gynoecium (Figure 15). Outside the group of six large bundles there is a single smaller bundle opposite each angle of the pedicel. Just below the receptacle each of these three bundles branches several times. Some of the branches unite with the sepal bundles and some provide the petals with all of their bundles except the large median one (Figure 15). Each petal median bundle is derived from the pedicel bundle opposite an angle. Each petal is therefore supplied from two pedicel bundles, both on the same radius.

The numerous small peripheral bundlesnot illustrated in Figure 15-supply the sepals with their numerous tiny abaxial bundles. The numerous and somewhat larger adaxial bundles of each sepal are derived from the internal pedicel bundle opposite each side of the pedicel (Figure 15).

Just above the level of the first branching of each internal bundle the petal median bundle departs. At this level the internal bundle opposite each angle is divided once. Slightly above this the stamen trunk bundles and the carpel bundles separate (Figure 15). The stamen trunk bundles branch rapidly above this level and eventually supply each of the numerous stamens and staminodia with one bundle. This dendritic vasculature of the androecium is similar to that found in some dicotyledons and it appears to be unknown in other monocotyledonous families except for the Alismaceae (Kaul, 1967). 
Figure 9. Longitudinal sections of two flower primordia. At left, very young stage before initiation of any appendages. At right, after initiation of perianth and first stamens (pointer), cf. Figure 1, X 60. | Figure 10. Longitudinal section at later stage. Carpels have appeared on flanks of apex and the upper, first-formed stamens have appeared, cf. Figure 2, $X$ 70. | Figure 11. Longitudinal section at still later stage. Upper stamens now noticeably larger than lower, laterformed ones. Carpel primordia appear as prominent dark masses at sides of apex. Residual apex prominent, X 60 . I Figure 12. Longitudinal section of nearly mature flower. Ovules are differentiating and the residual apex and elongate receptacle are distinct. Androecial shoulder developing as stamens and staminodia become aligned horizontally, cf. Figure 3, X 15. | Figure 13. Longitudinal section at anthesis. Pointer indicates residual apex, which is overtopped by the stigmatic margins. Vascular supply to ovules shown, cf. Figure 16. Androecial shoulder now slightly raised and first-formed stamens are overtopped by later ones and by staminodia, cf. Figure 4, X 11. | Figure 14. Cross section of flower just before anthesis at about the middle of the gynoecium. Seventeen carpels are united to the elongate axis and their ventral margins are conduplicately fused at this level. The carpels are essentially free from each other at this level. Dorsal and lateral bundles can be seen in each carpel. Aerenchymatous and laticiferous filaments of the androecium are crowded around the carpels, X 20.

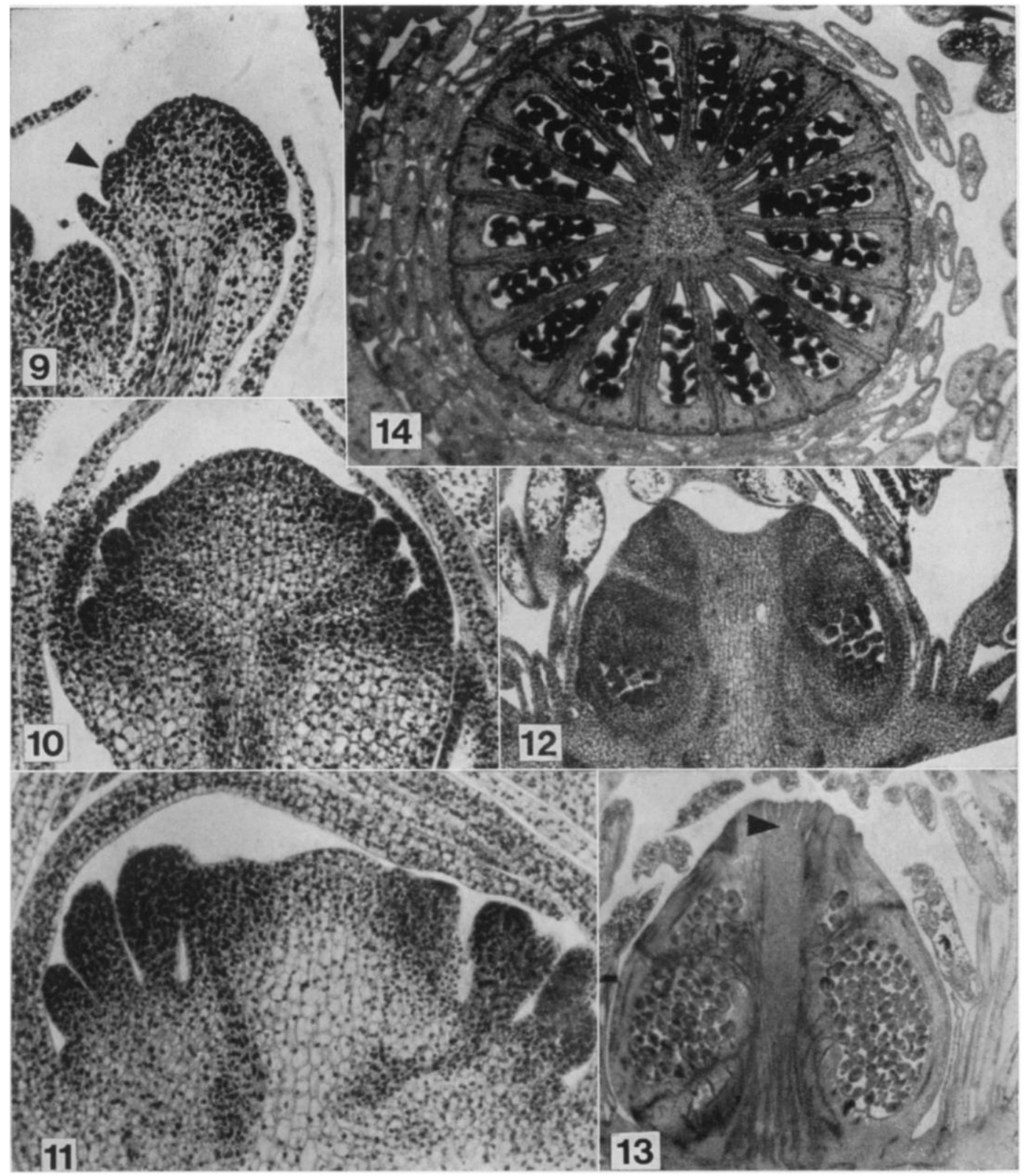


Figure 15. Vascular plan of flower at anthesis. Placental supply has been simplified in this drawing and some portions of the system have been cut away for simplification. Main sepal supply shown in white; the three bundles supplying the sepals are located opposite the sides of the triangular axis. Supply to petals, androepium, and gynoecium shown in black, X 10. I Figure 16. A single carpel and its vasculature in lateral view, X 16. p, petal median bundle; pl, placental bundles, simplified; se, sepal supply; st, stamen bundles.

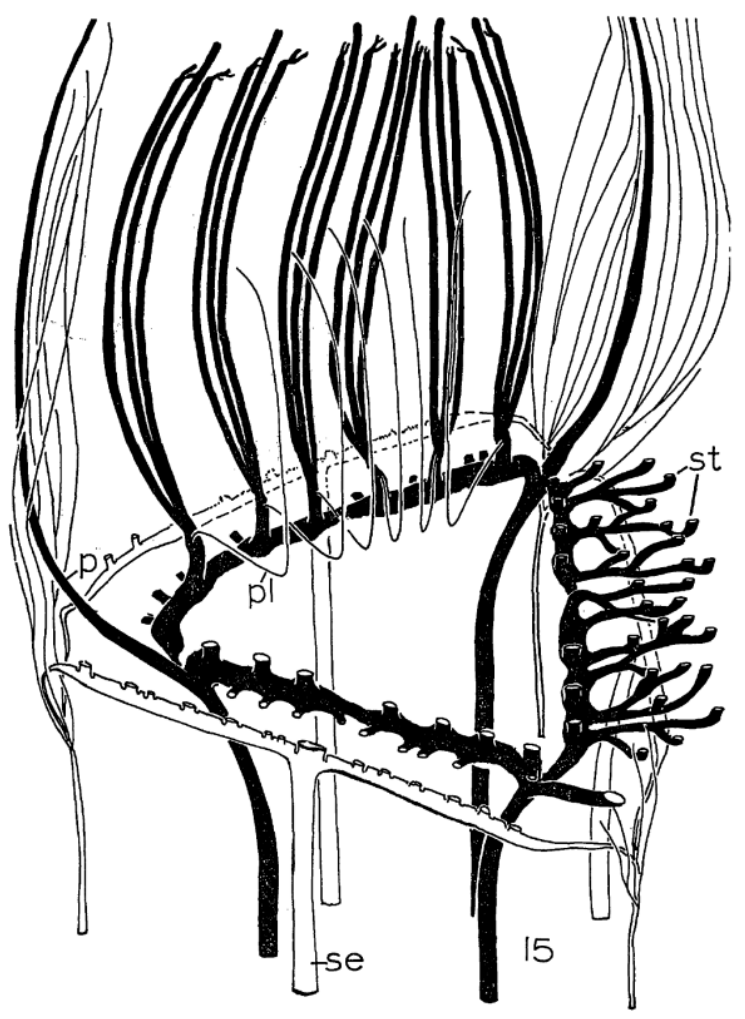

Above the departure of the trunk bundle to a group of stamens the carpel bundles proceed upward, each to a single carpel. It is not possible to detect whether the bundles to the carpels depart at one or at several levels. Just below the level of attachment of each carpel to the receptacle the single bundle serving that carpel is divided into three and all proceed upward through the median portion of the carpel (Figure 16). The middle one, the dorsal bundle, continues unbranched to the stigmatic region where it ends. The other two, the lateral bundles, are also unbranched up to the stigmatic region, but they branch within it (Figures 15 and 16).

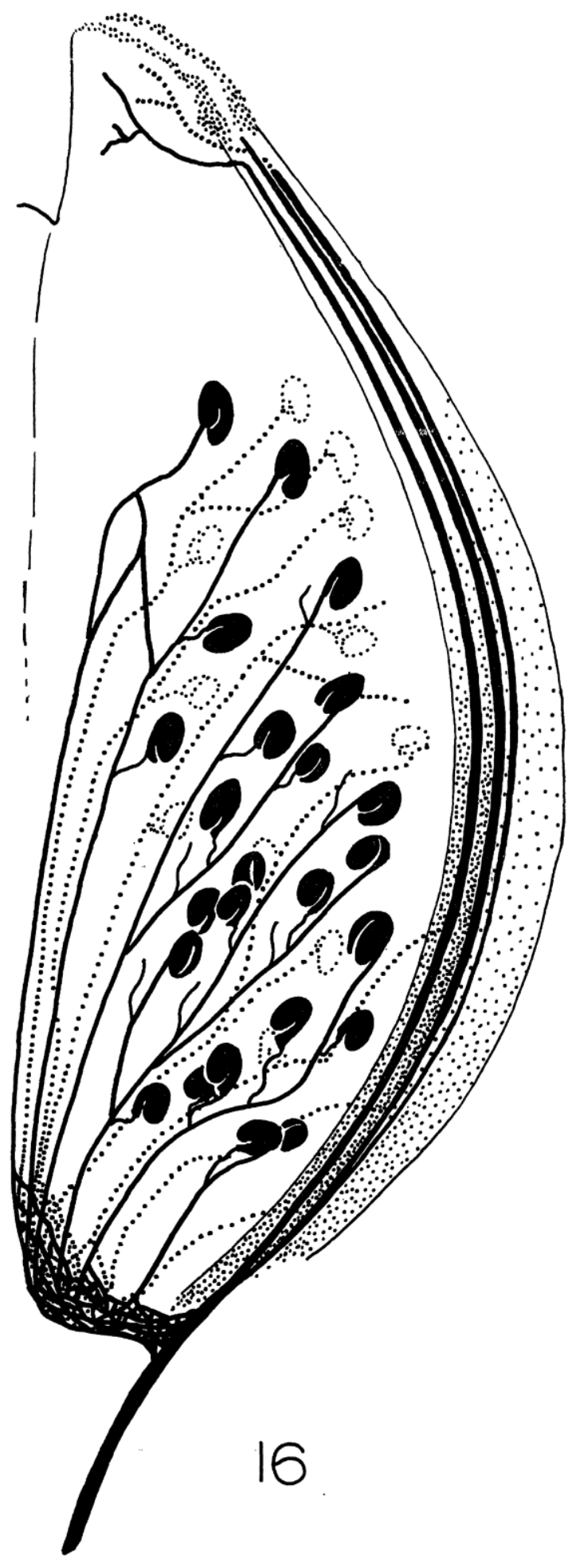


At the base of each carpel numerous small and greatly anastomosed bundles depart from the single carpel bundle below the level of separation of dorsal and lateral bundles. Although some of these tiny bundles appear to traverse the receptacle, no bundles have been observed which do not eventually lead to the placenta. These small bundles branch within each carpel wall and supply the numerous ovules (Figure 16). During ontogeny the dorsal bundle begins to differentiate first, followed by the laterals and the placental supply.

\section{Discussion}

The Limnocharis androecium is of the type which Corner (1946) described as massive for some dicotyledonous taxa. These show the typical features of the multistaminate centrifugal androecium: cessation of apical growth but continuation of radial growth of the floral primordium, initiation of the first stamens more or less alternate with the carpels, expansion of the floral disc between the initial staminal whorl and the perianth, and a slight tendency toward perigyny in the mature flower. He interpreted this type of androecium as a result of the cessation of apical growth but with retention of radial growth between the gynoecium and perianth, in contrast with the normal, centripetally developed massive androecium in which both apical and radial growth stop simultaneously. Accordingly, the massive centrifugal androecium has been derived from the massive centripetal androecium by changes in the directions of development of the floral bud.

The evidence from Limnocharis in general supports this interpretation, but the continuation of apical growth with the resulting residual floral apex while prominent radial growth is also occurring suggests a transitional growth pattern. In Limnocharis there are no prominent humps upon which numerous stamen primordia arise as have been reported for some dicotyledonous taxa. Corner (1946) has interpreted these humps as derivative conditions brought about by decreased size of the floral apex resulting in extreme crowding within the androecium; thus the resulting androecium is fasciculate. Although there is no external evidence of fasciculation in Limnocharis, the beginnings of fasciculation are suggested by the tendency for groups of stamens to arise in six sectors of the floral bud, the first groups to develop being the least-crowded, antisepalous ones. The dendritic vascular systems serving groups of stamens are also reminiscent of fasciculate androecia. Corner also showed that such massive primordia of groups of stamens arise on broad shoulders of the floral apex. In Limnocharis there are clearly no such shoulders at the time of appearance of the stamen primordia. Instead, these shoulders develop later (Figures 9-12) as a result of great cell enlargement and diffuse growth in the receptacle. The ontogenetic reorientation of the androecium from vertica to horizontal planes comes about in this way. With this reorientation there are changes in the configuration of the vascular system. The first-formed stamens of a vascular trunk system are at first above, and later inside of, the later-formed stamens and staminodia. The vascular bundles serving these later-formed members depart from the trunk beyond those serving the first-formed stamens, and this relationship is maintained during the development of the shoulders. In both the centripetal and the centrifugal androecium, then, it is the first-formed stamens which are borne proximally on the vascular system and the later-formed members are borne distally to them.

If the centrifugal androecium is truly a fundamentally different type of androecium the great systematic value sometimes ascribed to it is justified, and it would support the separation of Limnocharis and Hydrocleis with their centrifugally developed androecia from Butomus and Tenagocharis. If the centrifugal pattern is primitive within the family as it is now constituted, progressive sterilization of the last-formed members of the androecium as seen in Limnocharis and $\mathrm{Hy}$ drocleis could have given rise to the type of androecium of constant numbers of fertile organs found in Butomus and Tenagocharis.

The origin of the carpels on the flanks of the floral apex and their persistence in that position leaves no doubt that they are lateral organs. The successive origin of alternating whorls of carpels 
seen in Butomus and Hydrocleis is not present in Limnocharis, although the antisepalous carpels arise slightly ahead of the antipetalous ones.

The study of the development of the carpels of Limnocharis does not support Troll's (1932) contention that it is the basal margins of the carpels which have elongated and that the ventral margins are represented only by the margins which project beyond the floral apex. The ventral margins have become conduplicately appressed and fused in the lower portions, while continued growth of the floral apex has resulted in fusion of the margins with the receptacle. These fusions are possibly the results of crowding of the carpels against each other and against the receptacle. Other genera of the family lack the elongate receptacle and the numerous carpels and in them the ventral margins are only slightly fused basally. The carpels of Limnocharis are not fused with each other, however, except in the narrow ventral areas where they are buried in receptacular tissue (Figure 14).

Anatomical evidence suggests that it is the carpel walls with their associated placentae, rather than placentae alone, which form the ovuliferous laminae. Such placental proliferation has been suggested for the Butomaceae by Singh (1966b) and for the Papaveraceae and Rafflesiaceae by Puri (1952). Further, when the fruit dries the entire placental region with its seeds separates from the lamina.

The Limnocharis gynoecium is reminiscent of certain hypothetical apocarpous prototypes of Nymphaea suggested by Moseley (1961), and it has similarities to the modern flowers of Nymphaea (Moseley, 1961) and Nuphar (Moseley, 1965). In these two genera, as in Limnocharis, the placentation is laminar and the carpels are numerous. Some species are syncarpous and others are partially so, and various degrees of epigyny are shown. In all three genera there is a central receptacular core to which the ventral margins of the carpels are adnate, and all have conduplicate carpels. Moseley has attributed some modifications of the gynoecial vascular system of Nymphaea to the development of syncarpy and epigyny. The Limnocharis gynoecium, being essentially apocarpous, lacks these modifications of vasculature. Although the flower of Limnocharis is not epigynous, suggestions of incipient epigyny can be seen at maturity in the slightly raised androecial shoulder (Figure 13).

Within the Butomaceae progressive shortening of the receptacle is associated with reduction in number of stamens and carpels and with reduction in the vasculature of these organs (Kaul, 1964). The elongated receptacle and prominent residual floral apex of Limnocharis are the most primitive within the family. Tenagocharis and Hydrocleis nymphoides exhibit transitional types to the shortened receptacle of Butomus. There is a tendency toward reduction in carpel number in the family from the 18 or so of Limnocharis through nine in Tenagocharis specimens to six in some species of Hydrocleis and to three in others.

Phylogenetic patterns of reduction are more difficult to trace in the butomaceous androecium. It appears that the numerous centrifugally developed members of the Limnocharis androecium represent a primitive condition in the family. The reversal of the order of stamen development from centrifugal to centripetal in the family is possibly a concomitant of reduction of the massive androecium. Persistence of paired stamens in Butomus and Tenagocharis may also be explainable this way.

Literature Cited

Buchenau, F. 1857. Über die Blütenentwicklung von Alisma und Butomus. Flora 40: 241-256.

Corner, E. J. H. 1946. Centrifugal stamens. Journal of the Arnold Arboretum 27: 423-437.

Eames, A. J. 1961. Morphology of the angiosperms. McGraw-Hill, New York.

Eber, E. 1934. Karpellbau und Plazentationsverhältnisse in der Reihe der Helobiae. Flora 127: 273-330.

Kaul, R. B. 1964. A phylogenetic study of the flowers of the Butomaceae and the Hydrocharitaceae. Ph.D. thesis, University of Minnesota.

Kaul, R. B. 1967. Development and vasculature of the flowers of Lophotocarpus calycinus and Sagittaria latifolia (Alismaceae). American Joumal of Botany 54: 914-920.

Moseley, M. F., Jr. 1961. Morphological studies of the Nymphaeaceae. II. The flower of Nymphaea. Botanical Gazette 122: 233-259.

Moseley, M. F., Jr. 1965. Morphological studies of the Nymphaeaceae. III. The floral anatomy of Nuphar. Phytomorphology 15: 54-84.

Payer, J. B. 1857. Traité d'organogénie comparée de la fleur. Volume 1. Paris.

Puri, V. 1952. Placentation in angiosperms. Botanical Review 18: 603-651.

Ronte, I-I. 1891. Beiträge zur Kenntnisse der Blüthengestaltung einiger Tropenpflanzen. Planta 74: 492-529.

Saunders, E. 1929. On carpel polymorphism. III. Annals of Botany 43: 459-481.

Singh, V. 1966a. Morphological and anatomical studies in Helobiae. VII. Vascular anatomy of the flower of Butomus umbellatus Linn. Proceedings of the Indian Academy of Sciences 63: 313-320.

Singh, V. 1966b. Morphological and anatomical studies in Helobiae. X. Trends of specialization in placentation in Helobiae. Current Science 35: 250-251.

Troll, W. 1932. Beiträge zur Morphologie des Gynaeceums II. Über das Gynaeceum von Limnocharis Humb. et Bonpl. Planta 17: 453-460. 